S. W. STRATTON, Director

\title{
GRAPHIC COMPARISON OF SCREW THREAD PITCHES
}

Showing the Number of Threads per Inch and Pitch in Millimeters for both Inch and Millimeter Systems

\section{\begin{tabular}{l|l|l|l|l|l}
\hline & GRAPHICAL DETERMINATION OF THE \\
RELATION BETWEEN ENGLISH AND METRIC SCREW-THREAD PITCHES-By H. W. Bearce
\end{tabular}}

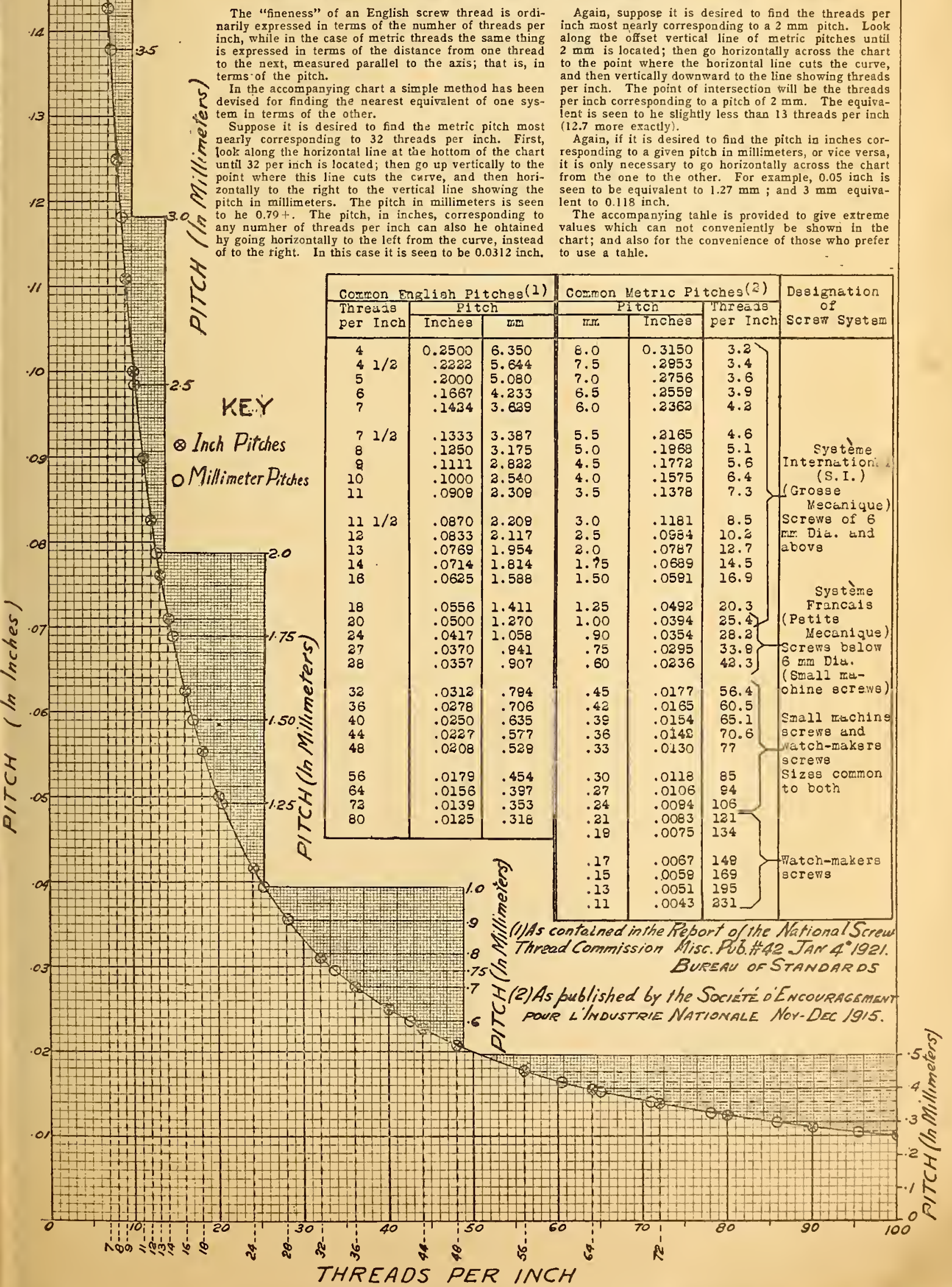


